\title{
B-Lymphocyte Antigen CD20
}

National Cancer Institute

\section{Source}

National Cancer Institute. B-Lymphocyte Antigen CD20. NCI Thesaurus. Code C38896.

B-lymphocyte antigen CD20 (297 aa, 33 kDa) is encoded by the human MS4A1 gene.

This protein plays a role in both the activation and proliferation of B-cells. 